\title{
Developing a Framework for Rural Electrification in India- Analysis of the Prospects of Micro-grid Solutions
}

\author{
Archan Bhanja ${ }^{1 *}$, Anil Kumar ${ }^{1}$, Anshuman K. Gupta ${ }^{2}$, Arijit K. Gupta ${ }^{3}$, Avishek Ghosal ${ }^{1}$, Subhashis Mukherjee ${ }^{4}$ \\ Saswata Chaudhury 5 \\ ${ }^{1}$ Department of Power Management, University of Petroleum \& Energy Studies, Dehradun 248007, India \\ ${ }^{2}$ Department of Economics, University of Petroleum \& Energy Studies, Dehradun 248007, India \\ ${ }^{3}$ Atos Global IT Solution, Bengaluru, India \\ ${ }^{4}$ Energy Sector, CEO - M2M Cybernetics, Delhi 110001, India \\ ${ }^{5}$ Economic \& Energy Sector, TERI, New Delhi 110003, India
}

Corresponding author: archanbhanja123@gmail.com

https://doi.org/10.18280/ijsdp.150821

Received: 28 September 2020

Accepted: 9 December 2020

\section{Keywords:}

micro-grid solutions, rural electrification, rural households, socio-economic development, hilly terrains

\begin{abstract}
The present research examines the perceptions of rural consumers towards the microgrid and rural electrification (RE) based solutions and develops a framework for improving the establishment of rural RE based microgrid solution captured from a case study in the Kalimpong district of North Bengal. The study adopted a mixed methodology study design includes the qualitative and quantitative aspects of the study through stakeholder interviews and questionnaire-based primary survey of the sample households. The perceptions received from sample households were validated with the response from other stakeholders, including academicians, researchers and sectoral experts. Data were analysed using structural equation modelling (SEM). The findings of the present research indicate that to accelerate the socioeconomic development of the hilly terrains of North Bengal region, multi-provider licensed based microgrid preferably with renewable-based is a preferred mode which ensures reliable and affordable access of electricity.
\end{abstract}

\section{INTRODUCTION}

Rural electrification is a key mechanism which could improve the standards of living in rural regions [1]. It has enormous environmental and socio-economic benefits and has the potential to improve livelihood through income-generating activities [2]. Furthermore, it opens up avenues for improving community services such as healthcare and education. Recently, India has achieved 100\% village electrification and 99.99\% household electrification [3]. However, getting $24 \times 7$ reliable and quality power supply is a significant challenge in many rural areas. In India, the electricity per capita consumption is deemed to be at around $566 \mathrm{KwH}$, which is relatively far below when compared with other developed and developing nations in the world. It is projected that the consumption of electricity in India will rise to more than 2200 kWh by the year 2021-22 [4].

India's high dependence to fossil fuel is evident from the fact that the nation's total supply of energy relies upon coal which is 55 per cent and more than 70 per cent of the total coal consumption is in the energy sector. Following coal, natural gas and crude oil are the commonly used energy sources for the power sector in the nation [5]. The use of fossil fuels continuously for the generation of conventional energy has set multiple challenges for policymakers and energy experts. In this regard, the need for renewable energy (RE) resources has been emphasized as a sustainable solution [6].

Due to infrastructural constraint and lack of profitable business opportunity, grid connectivity is not cost-effective in many parts of rural India. This led to the introduction and promotion of decentralized renewable energy systems for electrification via micro-grids, as an economically feasible solution [7]. The microgrid solutions are gaining momentum in recent years due to its ease of operation and remote working with both RE and fossil fuel-based power sources [8] to establish relatively large and stable generation system even in remote villages with thick forests or mountains [9].

The government of India (GOI), formulated several policies to support and implement microgrid [10]. The Electricity Act of 2003 was the first of its kind to include RE based off-grid systems as a part of the nation's solution to power generation. The National Electricity Policy and Rural Electrification Policy of 2006 also emphasized importance of decentralized distributed generation to facilitate a local distribution network of power. The new Tariff Policy set in the year 2016 also depicts microgrids as a source of power for villages that are remote and unconnected. Besides, the national mini-grid policy was also framed in the year 2016, which is still under consideration by the GOI [11].

Though the regulations and policies framed by the GOI have been incremental towards improving the stance of RE based microgrids in the nation, there are several challenges in association with such technologies. It is deemed that microgrids do not follow the standard economic model utilized in conventional power plants since the risks that are inherent in the isolated power systems are high. Due to ambiguities in policies and uncertainties in the generation of power, there is a difficulty in attracting investors to the isolated microgrid 
segment [12]. Besides, for Microgrids to achieve such benefits should have its implementation in an optimal location and size [13]. This estimated load is an important input for micro-grid sizing. Also while in the initial planning process of a microgrid system, accurately estimating the extreme equivalent load that the consumers are likely to enforce on the system poses a massive challenge. both micro-grid under-sizing and oversizing possess huge challenges to consumers and the government. This is because, the prospective consumers are little exposed to electrification. Given this scenario, predicting consumers who are actually interested in receiving electricity becomes difficult. It is challenging to forecast, even if consumers start using due to high time variation in the electricity demand created by them.

In addition, the intermittent nature of RE also leads to consumer frustration and dissatisfaction. This limited supply also significantly affects the amount of power supplied to the consumers. The increased need for external funding and the rate of the willingness of consumers towards RE based microgrid solutions creates excellent concern regarding the implementation of RE based microgrid solutions in the rural regions of the nation.

In West Bengal, according to census (2011) 2, 00,67, 299 $\mathrm{HHs}(55.7 \%)$ are electrified. Although the country has achieved $100 \%$ village electrification while access to electricity in rural areas is only limited to $42 \%$ HHs [14]. This indicates, still huge population relies on non-renewable and unclean energy sources like biomass, wood, charcoal and other petroleum products for basic needs. To alleviate these problems, in 1996, RE-based mini-grid was installed in the Sundarbans [15] with fifteen solar photovoltaic (PV)- based (total capacity $900 \mathrm{~kW}$ ), three biomass gasifier-based $(1,500$ $\mathrm{kW})$ and six wind solar hybrid model-based $(25 \mathrm{~kW}$ peak) mini-grids to cater the needs of 5,000 villages. Despite these initiatives, still access to electricity to many of the remote villages of west Bengal.

The demand for rural consumers acts as an essential parameter for the growth of RE based microgrid usage in the nation. While consumers value the power and reliability of electricity, there are limited options and financial conditions which force them towards choosing an appropriate electricity solution. It is deemed that an improved understanding regarding the more reliable versus powerful electricity could tend to predict the behaviour of consumers in the future wherein rural consumers might consider several attributes associated with the adoption of a specific electricity solution. When the electricity provided to consumers is less reliable, they might tend to value reliable solutions. In such a case, their perceptions tend to change towards a reliable system.

In this regard, it is imperative to understand the perceptions of customers towards microgrids and their willingness to pay (WTP) and adapt microgrid solutions. Therefore, the current study investigates and assesses the perceptions of rural consumers towards microgrid and their WTP RE based solutions. The study also identified socio-economic, demographic and techno-commercial penetration parameters that regulate WTP for a rural $\mathrm{HHs}$ electricity connection option. The findings of the study would enable develop a framework for improving the establishment of rural RE based microgrid solutions.

\section{LITERATURE REVIEW}

Recent studies have analysed the problems and challenges of the rural electrification plans and household willingness to pay (WTP) in both developed and developing countries. For instance, Bhandari et al. [16] assessed the WTP for the electricity generated through solar photovoltaics (PV) system among the villagers of a rural area. The findings showed a reduction of about $80 \%$ monthly expenses and a wider access to electricity could be achieved by using both collaborative consumptions equipped with the proper policies and regulations and community ownership. In rural Ethiopia, Entele [17], surveyed household's (HH)preference for renewable source of electricity and willingness to pay for solar PV electricity in addition to the gridline. HHs preferred gridline, irrespective of the payment scheme, while monthly instalment-based payment was preferred. Besides, factors such as income, education, age, location and amount of initial bid prices were important variables [18]. Ntanos et al. [19] reported a positive association between RES perceived advantages and WTP for RE. WTP was associated positively with education, energy subsidies and state support among Greece HHs.

For instance, Dugoua et al. [20] have reported the important geographic and socio-economic barriers of electrification in the Indian villages and identified that remoteness of village locations and population density of the regions pose a massive challenge for the electrifying the rural areas through grid extensions. Further, Quak [21] has reported that solar powerbased energy technologies offer significant costs saving in the electrification schemes of rural regions with low-density populations and fosters the socio-economic development of the concerned rural community. Also, Stadler [22] reported that the deployment of microgrid electrification systems using solar energy makes the rural region energy independent and decreases the environmental pollution caused by the burning of fossil fuels. On the other hand, Global Network on Energy for Sustainable Development, GNESD (2015) Larsen et al. [2] found that benefits of electrification are higher in gridconnected areas compared to areas connected through off-grid mode.

A review report done by Nigam et al. [23] have presented the development of smart grid technology and its future perspectives from an Indian context. The study has discussed the significant financial implications caused by the appropriate deployment of smart grid energy applications due to reduced power shortages, improvement in the reliability of power supply and management. The researchers have presented an overview of the Indian power market and identified that inadequate power infrastructure, mismanagement of demand, and supply of power as crucial challenges of rural electrification in India. The study has reported that the above challenges can be overcome by the appropriate deployment of smart grid technology-based applications resulting in cost reduction, proper integration of various electricity generation networks. On the other hand, Heynen, Lant, Smart, Sridharan, and Greig [24] recommended the adoption of microgrid energy systems using Solar Photovoltaic technology and wind energy to mitigate the challenges of unreliable electricity supply due to the reliance of only grid extensions for electrification in the rural regions of India. Graber and Narayanan [25] reported that the microgrids play a significant role in the rural electrification and consumer's willingness to pay for electricity in rural India is significantly influenced by the reliability and the price of the electricity provided by the energy systems. It is necessary to address various types of challenges for establishing rural electrification. These 
challenges are reliability, power quality, microgrid integration, variable energy generation and bi-directional power flow. There are technical challenges for implementing the microgrids, which focuses on control of operation based on the microgrid systems within the electrical area. Those are centralized control for optimization of the microgrid operations and can be emphasized on several strategies based on the interconnection of the microgrids and power grid. The techno-economic challenges in the case of rural microgrids are taken for establishing the principles of future microgrids. The other researchers have examined that within the industrialized countries, the microgrids are established for the generation of power by implementing high voltage transmission lines. There is minimal energy storage system associated with this microgrids system. The primary energy sources for these microgrids are carbon-based fossil-fuels which are used as the static entity and can travel with the small-scale distributed lines

Kabi et al. [26] have conducted a study to understand the social impacts caused by the implementation of solar home systems in the rural regions of Bangladesh. The study has reported that the comfort and the standard of living of the dwellers living in the rural regions of the country improved significantly with the installation of the solar energy-based equipment in their households. The findings of the study reported that the cost of the solar Home systems was the major constraint for the rural dwellers and the study recommended down-payment facilities and options like instalment for the purchase of the solar energy equipment would attract more number of low-income groups to adopt Solar House Systems technologies. The study also pointed out the improvements required in the quality of solar energy-based types of equipment and the after-sales service to attract the mass population to use the technology. The previous authors have evaluated that in some cases, people prefer to establish the solar-based solution for the rural electrification as that can be costly, unreliable as well as it may be unavailable. However, the chance of male employment is more in the case of a gridbased system organization. Thus, from the point of view of employability, the grid-based organization is preferred in rural electrification. Opiyo [27] conducted a study to evaluate the cost-effectiveness of Solar PV based systems in the electrification of rural areas of sub-Sahara regions and provided insights about the consumer preferences for the energy sources. The Study revealed that solar home systems were utilized only by the rich families of the community and the electrification in the majority of the community was primarily by the PV-based communal grids. However, Harrison et al. [28] reported that after the usage of pico-solar light, the children in the African community were able to extend their studies well into the night, thereby causing significant positive effects in the academic performance of the community children. The study compared the UN modern energy benchmark and reported that the low-cost pico-PV equipment would not be sufficient to achieve the UN recommended standard. The study identified that solar powerbased energy technologies are not preferred by the rural population in many developing countries, due to the high initial investments involved in establishing the infrastructure. Plutshack has emphasized on the rural electrification policy and the off-grid solar system within India and other developing countries. The establishment of microgrids for rural electrification comes under the goals of sustainable development (SDG7) established by the United Nations. Therefore, it is universally recommended that the microgrids system should be implemented by maintaining the planning and strategies within those rural areas.

Aditya has illustrated the model which is needed to establish as the microgrid operators in India. The alternative channels of the cost reduction system can be possible through grid feeding system, which is preferable to implement in various rural areas of India. It helps to reduce the grid electricity bills, and those microgrids can be utilized as the grid back-up at the time of cheaper cost, which can be compared to the 24-hours autonomous model. The previous authors have observed that the rural population is more concerned with exploitive business practices and the inequality of solar power within the villages. In these scenarios, the establishment of microgrids for rural development is a quiet right solution as that can help to overcome the issues for extra costing.

Melhem [29] explored the optimization techniques and energy management in smart grids. The study has examined problems in microgrid energy management, which includes different smart homes and microgrids in the background of Smart Grid. Reddy et al. [30] reviewed different optimization techniques for the development of smart grid comprising of renewable energy sources. However, the study has presented the review of stochastic programming, but detailed formulations in the occurrence of uncertainty and variability of renewable energy sources were not detailed in the study.

From the above review, it is evident that studies have focused on reviewing the problems and challenges in rural electrification; however, the researchers have not provided practical solutions for improving the rural electrification. Studies in the Indian context proved the feasibility of enabling Micro-grids in rural areas of India [31-34]. Even though Installation of microgrids has been a solution, it is riddled with reliability and efficiency problems. Hence it is necessary to identify the core issue to solve them by understanding the perceptions of rural consumers. Hence this study aims to examine the perceptions of rural consumers towards microgrid and rural electrification-based solutions and also aims to identify the socio-economic, demographic and technocommercial penetration parameters that determine WTP for a rural HHs electricity connection option thereby developing a framework for improving the establishment of rural RE based microgrid solutions. To attain the aim of the study, the following conceptual framework is adopted for the study (Figure 1).

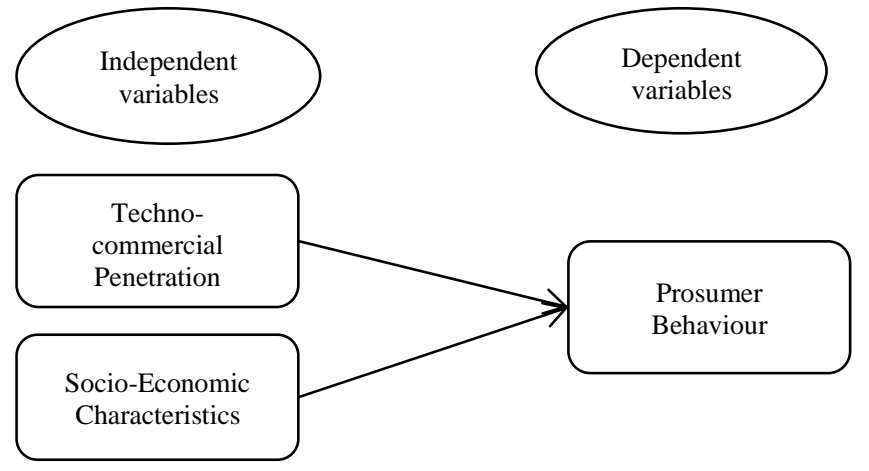

Figure 1. Conceptual framework 


\section{METHODS}

\subsection{Design of the study}

The study adopted an explanatory sequential mixed methodology design to examine the perceptions of customers towards microgrids and their attributes towards microgrid solutions. This research design is considered as one of the standard designs in the mixed methods research. In this design, there are two distinct interactive segments: first, the initial quantitative study is followed by a qualitative study. The explanatory design was applied to substantiate the quantitative findings with qualitative results [35]. The present research adopts a quantitative survey method and a qualitative interview method to attain the perception of rural electricity consumers towards the adoption of RE based microgrid solutions and to understand the policy mechanisms.

\subsection{Study area}

The study was conducted in Kalimpong sub-division, located in the hilly northern part of the Darjeeling district of the state of West Bengallocated in the eastern Himalaya region of India. The area is mainly covered in hilly and rugged mountain terrain.About $65 \%$ of the population are literate with 71 percent rural males were literate. The research site is bounded within $27^{\circ} 13^{\prime}$ ' North to $26^{\circ} 27^{\prime}$ 'North Latitude and 880 53' East to 870 59' East Longitude with an area of 3149 square kilometers. The Kalimpong municipality has a population of 49, 403 (2011 census). The altitude of the study area ranges from $15 \mathrm{~m}$ to $3602 \mathrm{~m}$ above the mean sea level. The region is influenced by the south-west and north-east monsoon while the temperature can drop close to zero degrees. Tectonic landscape includes the Gorubathan and Rangamati Surface [36]. In terms of geomorphology, the site consists of intermontane valley, piedmont fan plain, highly dissected hill slope, folded ridge, alluvial plain and active flood plain [37]. Figure 2 shows the map of Kalimpong.

\subsection{Sampling and sample size}

To examine the perception of rural consumers' willingness to adopt and pay, towards microgrid and rural electrification, the study adopted a stratified random sampling procedure, particularly the multi-stage sampling method. Darjeeling had three sub-divisions, Darjeeling Sadar Sub-Division, Kalimpong and Kurseong Sub-division. Among three, Kalimpong was chosen randomly that includes Kalimpong-I, Kalimpong-II and Gorubathan Community Development Blocks and Kalimpong Municipality. Data was collected in all the four divisions of Kalimpong using systematic random sampling method. In order to estimate the sample size for the study, a widely accepted rule of thumb as 10 cases per indicator variable in setting a lower bound of adequate sample size or reasonable sample size for a simple CFA model as 200 [38]. In line with this, the study targeted a sample size of 350 , considering a 10 percent attrition rate.

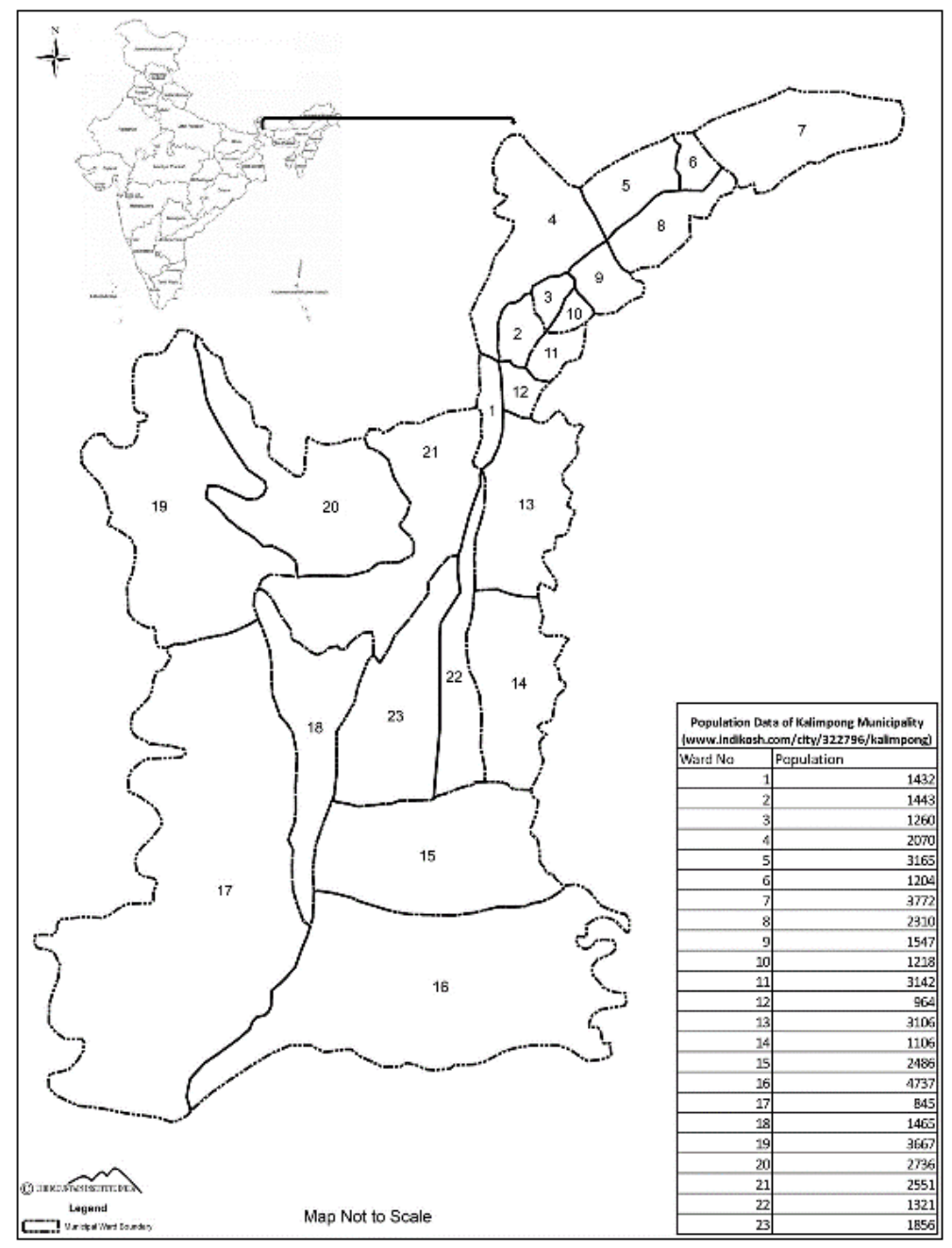

Figure 2. Kalimpong town municipality and wards 


\subsection{Survey design}

A structured questionnaire was designed to probe their perception of microgrids among the households. The survey questionnaire consists of four sections. Section I contains general information about the participants, section II consists of questions related to Techno-commercial Penetration, while section III consists of questions on Socio-economic Characteristics, and finally, Section IV consists of questions on Prosumer Behavior (Willingness to Pay and Adapt). The questionnaire for the survey was created based on discussion and mutual agreement with the research supervisors and several industry experts. The survey determines the willingness of rural consumers towards paying for RE based microgrid solutions wherein the responses provide the premise for the development of a rural RE framework

Another set of interview guide comprised of both closed and open-ended questions was created through multiple iterations with several subject matter experts, industry specialists and research supervisors. The interview guide also consists of 4 sections. Section I contains General Information and Investment Opinion of the respondents, Section II contains Government Policy and Legal Provisions, whereas Section III contains Techno-commercial Perspective and finally, Section IV contains Socio-Economic Behavioural Pattern of the Prosumers.

\subsection{Data collection}

The study included the experts from rural electrification, solar P.V. areas, solar home systems (SHS) experts, administrative-economic-financial-social sector experts, shopkeepers and the owners of small-scale businesses as a sample population of the study. To explore the perceptions towards the proposed microgrid framework towards the target geography of the Hilly rural terrains of North Bengal, qualitative data was collected. Experts [39] suggest a range between 20 and 30 interviews be adequate sample or based on the concept of saturation for qualitative research. Interviews with key institutional stakeholders were undertaken to validate and verify the results obtained from the quantitative data and reviews. The stakeholders and specialists, including policymakers, academicians, and industry leaders and entrepreneurs, were representing Small Medium enterprises (SMEs). In this study, twenty-five interviews were although targeted, thematic saturation was achieved following completion of twenty-one interviews $(n=21)$.

\subsection{Data analyses}

Data was analysed using SPSS 20.0 version (IBM). Descriptive statistics was used to summarize and present the data to frequency and percentage of the demographical information of respondents. The independent samples t-test was used to compare two groups on the mean value of a continuous normally distributed variable. The association and correlation between multiple attributes were evaluated using the chi-square test. Structural Equation Modeling (SEM) was applied to examine the association between independent and dependent variables. The data collected from the interviews were grouped into themes. The thematic analysis consists of six phases [40]: First, the data collected from the interviews were translated to identify the most relevant inference from the participants. Further, initial codes were generated with the relevant inference form the participants. Subsequently, the distinct elements known within a data set were grouped into themes, and then a systematic review of the themes were identified. Finally, the apparent and coherent explanation was given, which refers to the data outlined in the thematic matrix.

\section{RESULTS}

In total, 337 participants respondent the survey while twenty-one interviews were carried out. The following section presents the findings of the quantitative and qualitative data.

\section{i) Quantitative data analysis observations}

Table 1 presents the descriptive statistics of the participants. represents that majority of the participants $57.3 \%$ were male, and $42.7 \%$ were female in which $42.4 \%$ of the participants are between the age group of $30-40$ years and $90.8 \%$ of the respondents have electricity connection at their home. Also, around $47.5 \%$ of the respondents have $<0.5 \mathrm{~km}$ distance from their home to the electric supply office. Around $44.2 \%$ of the respondents pay 2-5 INR per unit for electricity. It is also observed that, approx. $57.3 \%$ of the respondents stated that the $\mathrm{SEB} /$ State Utility is the sole electricity supply provider in their localities and 59.6 of the respondents have stated that they have Micro-finance Institutions (MFIs) in their locality.

Table 1. Frequency of personal information of the respondents

\begin{tabular}{|c|c|}
\hline & $\begin{array}{l}\text { Frequency } \\
(\mathbf{n}, \%)\end{array}$ \\
\hline \multicolumn{2}{|l|}{ Gender } \\
\hline Male & $193(57.3)$ \\
\hline Female & $144(42.7)$ \\
\hline \multicolumn{2}{|c|}{ Age (in years) } \\
\hline $18-30$ & $48(14.2)$ \\
\hline $30-40$ & $143(42.4)$ \\
\hline $40-50$ & $111(32.9)$ \\
\hline $50-60$ & $30(8.9)$ \\
\hline$>60$ & $5(1.5)$ \\
\hline \multicolumn{2}{|l|}{ Electrical Connection at Home } \\
\hline Yes & $306(90.8)$ \\
\hline \multicolumn{2}{|c|}{ Distance to the Electric supply office } \\
\hline$<0.5 \mathrm{~km}$ & $160(47.5)$ \\
\hline $0.5-2 \mathrm{~km}$ & $120(35.6)$ \\
\hline $2-5 \mathrm{~km}$ & $55(16.3)$ \\
\hline$>5 \mathrm{~km}$ & $2(0.6)$ \\
\hline \multicolumn{2}{|c|}{ Price of electricity paid per unit/ $\mathrm{kWh}$} \\
\hline $2-5$ INR & $149(44.2)$ \\
\hline $5-7$ INR & $62(18.4)$ \\
\hline$>7 \mathrm{INR}$ & $5(1.5)$ \\
\hline Not Known & $121(35.9)$ \\
\hline \multicolumn{2}{|l|}{ Service Provider in Locality } \\
\hline SEB/State Utility & $193(57.3)$ \\
\hline Group Supply/Co-operative & $129(38.3)$ \\
\hline Panchayat/ Municipality & $2(0.6)$ \\
\hline Not Known & $13(3.9)$ \\
\hline \multicolumn{2}{|c|}{$\begin{array}{l}\text { Micro-finance Institutions (MFIs) presents in } \\
\text { locality }\end{array}$} \\
\hline Presence of MFI & $201(59.6)$ \\
\hline Total & $337(100.0)$ \\
\hline
\end{tabular}

Table 2 reveals reliability Analysis, descriptive statistics and correlation analysis for study variables. From the table, it is depicted that Socio-economic Characteristics $(r=-0.151)$ 
and prosumer behaviour $(\mathrm{r}=-0.261)$ and thus there is a negative relationship among prosumer behaviour, socioeconomic characteristics and techno-commercial penetration. Furthermore, the descriptive statistics contains Mean, standard deviation, Maximum and Minimum values for the study variable. The mean and S.D. of techno-commercial penetration is $3.088 \& 0.580$ respectively, followed by the mean and S.D. of Socioeconomic Characteristics is 2.962 and 0.621 respectively, and the mean and S.D. of Prosumer Behaviour is 3.802 and 0.835 respectively. Also, Cronbach's alpha value for techno-commercial penetration is 0.339 , prosumer behaviour is 0.435 , and socioeconomic characteristics is 0.215 . Figure 3 represents the confirmatory Factor analysis which shows the relationship between the study variables.

Table 2. Reliability analysis and descriptive statistics with correlation analysis

\begin{tabular}{cccc}
\hline & $\begin{array}{c}\text { Techno- } \\
\text { commercial } \\
\text { Penetration }\end{array}$ & $\begin{array}{c}\text { Socio-economic } \\
\text { Characteristics }\end{array}$ & $\begin{array}{c}\text { Prosumer } \\
\text { Behaviour }\end{array}$ \\
\hline $\begin{array}{c}\text { Techno- } \\
\text { commercial }\end{array}$ & 1 & & \\
$\begin{array}{c}\text { Penetration } \\
\text { Socio-Economic } \\
\text { Characteristics } \\
\text { Prosumer }\end{array}$ & $-.151^{* *}$ & 1 & \\
Behaviour & $-.261^{* *}$ & $-.539^{* *}$ & 1 \\
\hline $\begin{array}{c}\text { Mean } \\
\text { SD }\end{array}$ & 3.088 & 2.962 & 3.802 \\
Min & 0.580 & 0.621 & 0.835 \\
Max & 2.00 & 1.50 & 1.00 \\
Cronbach's & 4.33 & 4.50 & 4.50 \\
alpha & 0.339 & 0.215 & 0.435 \\
\hline
\end{tabular}

TCP - Technocommerical penetration, SEC- Socioeconomic characteristics, PB- Prosocial behaviour

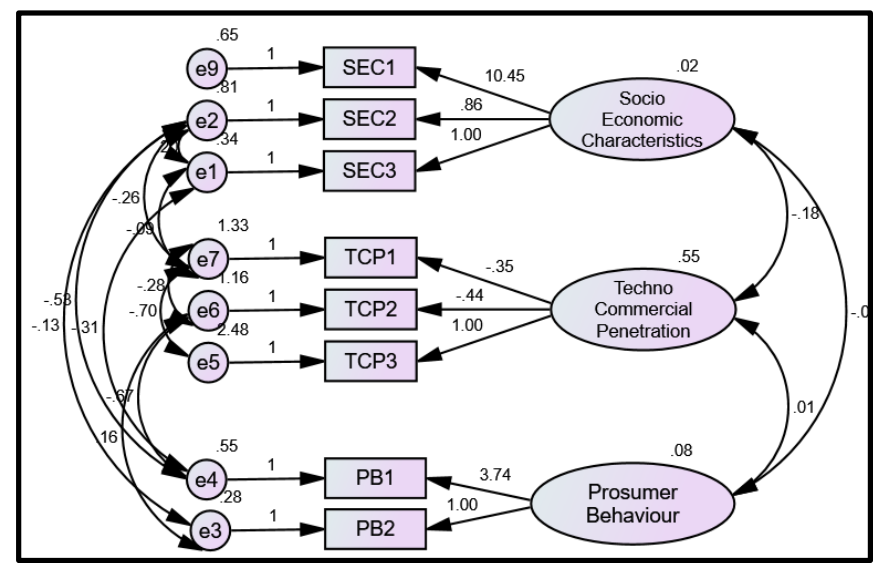

Figure 3. Confirmatory factor analysis

TCP - Technocommerical penetration, SEC- Socioeconomic characteristics, PB- Prosocial behaviour

Table 3 represents the association between the study variables using CFA analysis. The model summary reveals that the model was a good fit as the factors were found to be significant at the $\mathrm{p}>0.05$. With the help of the global fit (seven different fit indices), this study model was evaluated. This model is said to be good fit as the quality of fit was acceptable representation of the sample data $(\chi 2(7)=12.100$, GFI $($ Good Fit Index) $=0.991$, RFI $=0.960$, NFI (Normed Fit Index) $=0.990 ;$ IFI (Incremental fit index) $=0.996$. Similarly, CFI $=0.996$ and RMR (Root Mean Square Residuals) $=0.045$, and RMSEA (Root Mean Square Error of Approximation) $=0.047$ values are lower the 0.08 critical value. Figure 4 represents the SEM model which shows the relationship between the dependent variable and independent variables using path diagrams.

Table 4 represents the association between dependent and independent variables using path diagrams. The model summary reveals that the model is a good fit as the factors are found to be significant at the $p>0.05$. With the help of the global fit (seven different fit indices), this study model is evaluated. This model is said to be good fit as the quality of fit was acceptable representation of the sample data $(\chi 2(5)=$ 18.570, GFI (Good Fit Index) $=0.985$, RFI $=0.903$, NFI $($ Normed Fit Index $)=0.977$; IFI $($ Incremental fit index $)=0.983$. Similarly, CFI $=0.983$ and RMR (Root Mean Square Residuals) $=0.058$, and RMSEA (Root Mean Square Error of Approximation $)=0.070$ values are lower the 0.08 critical value.

\section{ii) Qualitative data analysis observations}

Further below are the observations that we have derived, based on our qualitative data analysis resulted from the interviews with the different level of stakeholders:

1. We observed that sectoral experts, among which majority were Industry experts (28.6\%), Entrepreneurs (19\%), policymakers (19\%) and academicians (14.3\%), have indicated to adapt multi-provider license-based gridconnected ecosystem (38.1\%) for rural electrification and socio-economic development in the hilly terrains of North Bengal.

2. We have also identified that the specialists have also preferred to adapt the self-help group (28.6\%) and Group supply (19\%) driven cooperative model in order to speed up this rural electrification model.

3. While the Gram panchayats/ municipalities were identified as the highest-ranking preferred investing agency (28.5\%) for community funding to ensure the desired rural electrification and growth model at present, soon the private operators $(57.1 \%)$ were the highest-rank choice for such rural electrification mission, along with the self-help group to run it.

4. We have also observed that the specialist respondents majorly believe that the Rural BPL populations get the necessary Govt. subsidy declared by the Union Govt. (23.8\%).

5. The specialists have identified reliable electricity supplybased energy security, $100 \%$ electrification for rural India $(42.7 \%)$ and provisioning for an additional source of income for rural population through solar power micro-grid as the highest-ranking priorities for Govt.

6 . The specialists have identified the following key drivers for adaptation of the solar power based microgrid by the rural population:

a) Environmental factor together with reliable green energy (38.1\%)

b) Availability of necessary provider and resources for affordable energy (28.5\%)

c) Provision for Govt. financial aid as rural electrification subsidy $(23.8 \%)$. 
Table 3. Confirmatory factor analysis

\begin{tabular}{|c|c|c|c|c|c|c|}
\hline & & & $\begin{array}{c}\begin{array}{c}\text { Unstandardized } \\
\text { Co- } \\
\text { efficient }\end{array} \\
\end{array}$ & S.E & $\begin{array}{l}\text { Standardized } \\
\text { coefficient }\end{array}$ & p-value \\
\hline PB2 & $<---$ & Prosumer Behaviour & 1 & & 0.478 & \\
\hline PB1 & $<---$ & Prosumer Behaviour & 3.74 & 0.769 & 0.825 & $<0.0001 * * *$ \\
\hline TCP3 & $<---$ & Techno-commercial Penetration & 1 & & 0.426 & \\
\hline TCP2 & $<---$ & Techno-commercial Penetration & -0.436 & 0.053 & -0.288 & $<0.0001 * * *$ \\
\hline TCP1 & $<---$ & Techno-commercial Penetration & -0.345 & 0.044 & -0.216 & $<0.0001 * * *$ \\
\hline SEC3 & $<---$ & Socio-Economic Characteristics & 1 & & 0.208 & \\
\hline SEC2 & $<---$ & Socio-Economic Characteristics & 0.859 & 0.379 & 0.117 & $0.024 *$ \\
\hline SEC1 & $<---$ & Socio-Economic Characteristics & 10.448 & 2.568 & 0.847 & $<0.0001 * * *$ \\
\hline \multicolumn{7}{|c|}{ Model Summary } \\
\hline \multicolumn{3}{|c|}{ Chi-square value $\left(\chi^{2}\right)$} & \\
\hline \multicolumn{2}{|c|}{ Degrees of freedom (df) } & 7 & & & & \\
\hline \multicolumn{2}{|c|}{ P value } & 0.097 & \multicolumn{4}{|c|}{ P-value $>0.05$ (Hair et al., 2006) } \\
\hline \multicolumn{2}{|c|}{ GFI } & 0.991 & \multicolumn{4}{|c|}{$>0.90$ (Daire et al., 2008) } \\
\hline \multicolumn{2}{|c|}{ RFI } & 0.960 & \multicolumn{4}{|c|}{$>0.90$ (Hair et al., 2006) } \\
\hline \multicolumn{2}{|c|}{ NFI } & 0.990 & \multicolumn{4}{|c|}{$>0.90$ (Hair et al., 2006) } \\
\hline \multicolumn{2}{|c|}{ IFI } & 0.996 & \multicolumn{4}{|c|}{ > 0.90 (Daire et al., 2008) } \\
\hline \multicolumn{2}{|c|}{ CFI } & 0.996 & \multicolumn{4}{|c|}{$>0.90(\mathrm{Hu}$ and Bentler, 1999) } \\
\hline \multicolumn{2}{|c|}{ RMR } & 0.045 & \multicolumn{4}{|c|}{$<0.08$ (Hair et al., 2006) } \\
\hline \multicolumn{2}{|c|}{ RMSEA } & 0.047 & \multicolumn{4}{|c|}{$<0.08$ (Hair et al., 2006) } \\
\hline
\end{tabular}

$* * * p<0.001, * * p<0.01, * p<0.05$

TCP - Technocommerical penetration, SEC- Socioeconomic characteristics, PB- Prosocial behavior

Table 4. Structural equation model

\begin{tabular}{|c|c|c|c|c|c|c|}
\hline & & & Unstandardized coefficient & S.E & Standardized coefficient & p-value \\
\hline TCP3 & $<---$ & $\begin{array}{c}\text { Techno- } \\
\text { commercial } \\
\text { Penetration }\end{array}$ & 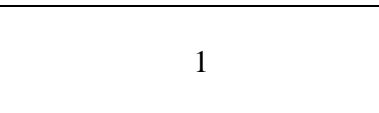 & & 1.011 & \\
\hline TCP2 & $<---$ & $\begin{array}{l}\text { Techno- } \\
\text { commercial } \\
\text { Penetration }\end{array}$ & 2.114 & 1.297 & 3.324 & 0.103 \\
\hline TCP1 & $<---$ & $\begin{array}{l}\text { Techno- } \\
\text { commercial } \\
\text { Penetration }\end{array}$ & -0.3 & 0.353 & -0.441 & 0.396 \\
\hline SEC3 & $<---$ & $\begin{array}{l}\text { Socio-Economic } \\
\text { Characteristics }\end{array}$ & 1 & & 0.259 & \\
\hline SEC2 & $<---$ & $\begin{array}{l}\text { Socio-Economic } \\
\text { Characteristics }\end{array}$ & 2.066 & 0.293 & 0.352 & $<0.0001 * * *$ \\
\hline SEC1 & $<---$ & $\begin{array}{l}\text { Socio-Economic } \\
\text { Characteristics }\end{array}$ & 1.709 & 0.433 & 0.173 & $<0.0001 * * *$ \\
\hline $\mathrm{PB}$ & $<---$ & $\begin{array}{c}\text { Techno- } \\
\text { commercial } \\
\text { Penetration }\end{array}$ & 0.046 & 0.079 & 0.096 & 0.565 \\
\hline PB & $<---$ & $\begin{array}{l}\text { Socio-Economic } \\
\text { Characteristics }\end{array}$ & -8.042 & 3.968 & -1.47 & $0.043 *$ \\
\hline
\end{tabular}

\begin{tabular}{ccc}
\hline & \multicolumn{2}{c}{ Model Summary } \\
\hline $\begin{array}{c}\text { Chi-square value }\left(\chi^{2}\right) \\
\text { Degrees of freedom }\end{array}$ & 18.570 & \\
(df) & 5 & \\
P value & 0.002 & P-value $>0.05$ (Hair et al., 2006) \\
GFI & 0.985 & $>0.90$ (Daire et al., 2008) \\
RFI & 0.903 & $>0.90$ (Hair et al., 2006) \\
NFI & 0.977 & $>0.90$ (Hair et al., 2006) \\
IFI & 0.983 & $>0.90$ (Daire et al., 2008) \\
CFI & 0.983 & $>0.90$ (Hu and Bentler, 1999) \\
RMR & 0.058 & $<0.08$ (Hair et al., 2006) \\
RMSEA & 0.070 & $<0.08$ (Hair et al., 2006)
\end{tabular}

$* * * p<0.001, * * p<0.01, * p<0.05$

TCP - Technocommerical penetration, SEC- Socioeconomic characteristics, PB- Prosocial behaviour

The stakeholders have identified that the National capacitybuilding schemes, National Rural Livelihood MissionNRLM (42.9\%), National rural employment and selfemployment schemes $(14.3 \%)$ could be the highest-ranking social inclusion levers. Moreover, these could be leveraged to establish the proposed solar power microgrid model robustly, along with rural electrification objective linked Incentive model $(38 \%)$ for the utility workforce and flexible, easy 
financing and convertible loan provisions (23.6\%) for the participating utilities.

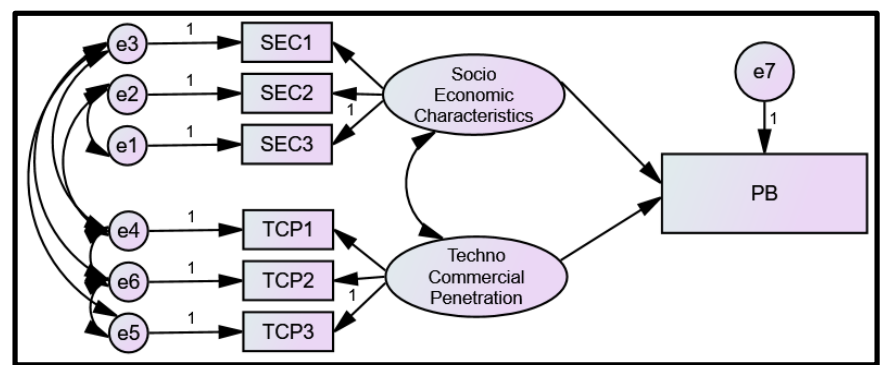

Figure 4. Structural equation model

TCP - Technocommerical penetration, SEC- Socioeconomic characteristics, PB- Prosocial behaviour

\section{DISCUSSION}

The study estimated socio-economic, demographic and techno-commercial penetration parameters that determine WTP for a rural HHs electricity connection option in the Kalimpong district of North Bengal. Most of the respondents indicated their willingness to take up electrification technologies using non-conventional energy for electrifying their households, with more than half of the respondents revealed that getting free electricity is the motivating factor for adopting non-conventional energy-based electrification. This is because, majority of the HHs belong to lower-income and the illiterate which could be attributed to the limited affordability of electricity in the Kalimpong district of North Bengal. Besides, in this state, the electricity access is solely provided by SEB/state utility. This indicates that prospects of electrifying the region through the deployment of microgrid energy technologies are high. Our study findings are in contradictory with Blankenship et al. [41] where no such evidence for sense of entitlement - the belief that government should offer basic goods and service for free as a predictor of low WTP. On other hand, studies demonstrated the provision of incentives [42], monthly instalment-based payment [17], collaborative consumption and community ownerships [16].

The factor 'willingness to pay' for reliable electricity is not significantly influenced by gender and age groups. However, education and income found to play a significant role in WTP. The households who earn comparatively higher incomes are willing to pay an additional amount for accessing reliable electricity supply to their households in contrast to the families whose income level is low. This disparity in the income earnings determines the capacity and the willingness to access high-cost electricity among the rural households of the region. Our study findings corroborate with the economic theory of normal good (electricity is normal good) that implies that participants with higher income, have higher WTP for electricity services. The present study findings are in line with the study by Entele [17] where rural HHs WTP is influenced by income level, and education and others [43, 44]. Our findings are consistent with the theoretical models, where low HHs income declines the WTP.

It is observed that the respondents do not have any inhibition to pay for electricity if its access is going to bring significant benefits to the families in the form of affordability and additional income-earning opportunities. Our study findings are in line with Lee et al. [45], where Korean consumers are WTP for the replacement considering the backup and opportunity costs. Hence from the study, it is clear that electricity is recognized as an essential parameter in socioeconomic development.

The findings revealed that there exists a definite relationship between the interest level of the respondents for using nonconventional energy sources for home electrification and the driving factor to adopt non-conventional energy sources based on technologies. This indicates that the Government needs to provide appropriate incentives to motivate the families to adopt renewable energy-based energy systems for home electrification. However, the survey findings reveal that the government subsidies and other benefits do not reach around $40 \%$ of the respondents, which indicates that the driving factor for home electrification is strong enough among the study samples. Besides, survey findings indicate that the awareness level about the benefit schemes offered by the Government for BPL consumers is relatively low among the majority of the study respondents.

In order to accelerate rural electrification in the study region, the subject-matter experts recommended the Gram panchayats/municipalities as the most preferred investing agency in the present days and have noted that the future rural electrification schemes need to actively motivate the participation of private sector operators and self-help groups to achieve maximum benefits. They have also recommended the deployment of solar power based microgrids energy systems to create opportunities for the rural inhabitants in such hilly terrains to earn additional income. In this context, these specialist respondents of the study have put forth environmental protection, affordable energy development financial aids and subsidies from the Indian Government as the important vital drivers that necessitate the use of solar power based microgrid systems for electrifying rural regions of the country. In this regard, these specialists have stressed the importance of leveraging the Government schemes such as National Capacity building schemes and National Rural Livelihood Mission (NRLM) and National rural employment \& Self-employment schemes to reap maximum benefits from the proposed solar power-based energy systems for rural electrification. The other recommendations include the provision of attractive incentives for the utility workforce, flexible (monthly installment scheme), easy financing, collaborative model [16] and convertible loan provisions will facilitate the active engagement and the participation of various stakeholders associated with the rural electrification process through the use of robust solar power-based energy systems.

\section{CONCLUSION}

The usual mode of electricity supply through the central grid extension is not always feasible to match the electricity demand of the rural households situated in the study region. From the findings, it can be concluded that the rural inhabitants are quite willing to pay additional money for accessing a reliable electricity supply and are quite favorable for adopting non-conventional energy sources-based electrification systems. The main conclusion of this study is that that the rural populations in the hilly terrains of North Bengal are interested in the adoption of solar power-based energy systems and expect appropriate incentives as the motivating factor for taking up the non-conventional energy sources for their energy needs. However, the study findings 
further indicate that the Government needs to initiate adequate measures to create wide-spread awareness of the financial aids and incentives provided for adapting non-conventional energy sources to empower the rural households, which will facilitate the rural population to make a shift from using traditional fuels to solar power based electricity systems for their energy needs. The stakeholders surveyed in the study have recommended essential priorities of the Government to achieve desired success in the rural electrification measures that include achieving energy security based on reliable electricity supply and planning for $100 \%$ electrification of rural India. The subject experts involved in the study have recommended the deployment of a group supply-driven cooperative model along with the active engagement of self-help groups to ensure quality supply in the hilly regions of North Bengal.

\section{Study implications}

The study findings indicate that the Government needs to initiate adequate measures to create wide-spread awareness of the financial aids and incentives provided for adapting nonconventional energy sources among the rural households, which will facilitate the rural population to make a shift from using traditional fuels to solar power based electricity systems for their energy needs. The stakeholders surveyed in the study have recommended essential priorities of the Government to achieve desired success in the rural electrification measures that include achieving energy security based on reliable electricity supply and planning for $100 \%$ electrification of rural India. The subject experts involved in the study have recommended the deployment of a group supply-driven cooperative model along with the active engagement of selfhelp groups to ensure quality supply in the hilly regions of North Bengal.

This study will be quite helpful to indicate the urgent need of developing suitable microgrid energy systems involving non-conventional energy sources for electrifying the unelectrified households of the Kalimpong district of North Bengal, as no significant studies in the similar topic have been conducted. The findings of the study can be useful in understanding the specific requirements of the rural inhabitants living in the hilly terrains of the North Bengal relating to adopting clean energy sources-based energy technologies, which will facilitate the Government to plan suitable subsidies and incentives for the active engagement of rural communities. The Government needs to take into careful consideration the consumer's willingness to pay the criteria of the rural households while setting the electricity tariff for the particular rural region. However, the findings arrived on willingness to pay criteria from this study may not be entirely representative of the other rural regions considering the limited sample surveyed in the study. Future researches can explore the opportunities and challenges involved in the integration of the central grid and the microgrid energy systems using locally available renewable energy resources, which will ensure reliable and quality supply of electricity at an affordable cost for the rural regions of the country.

\section{REFERENCES}

[1] Practical Action. (2018). Poor People's Energy Outlook 2018: Achieving Inclusive Energy Access at Scale. Practical Action Publishing Limited. https://infohub.practicalaction.org/bitstream/handle/112 83/621079/PPEO_Web_lowres.pdf?sequence=1;

[2] Ackom, E., Mackenzie, G.A., Larsen, T.H. (2016). Sustaining Energy Access Lessons from Energy Plus Approach and Productive Use in Developing Countries. Global Network on Energy for Sustainable Development (GNESD).

[3] Saubhagya. (2020). Pradhan Mantri Sahaj Bijli Har Ghar Yojana. https://www.india.gov.in/spotlight/pradhanmantri-sahaj-bijli-har-ghar-yojana-saubhagya.

[4] Garg, P. (2012). Energy scenario and vision 2020 in India. Journal of Sustainable Energy and Environment, 7-17.

[5] U.S. Energy Information Administration. (2014). India is increasingly dependent on imported fossil fuels as demand continues to rise. https://www.eia.gov/todayinenergy/detail.php?id=1755 1.

[6] Jain, M., Mital, M., Syal, M. (2016). Rural Electrification through solar energy: Insights from Chattisgarh State of India. International Journal of Environment \& Sustainabitity, $\quad 5(2)$ : https://doi.org/10.24102/ijes.v5i2.678

[7] Comello, S.D., Reichelstein, S.J., Sahoo, A., Schmidt, T.S. (2017). Enabling mini-grid development in rural India. World Development, 93: 94-107. https://doi.org/10.1016/j.worlddev.2016.12.029

[8] Ministry of New and Renewable Energy. (2015). Annual Report.

[9] Ali, A., Li, W., Hussain, R., He, X., Williams, B., Memon, A. (2017). Overview of current microgrid policies, incentives and barriers in the European Union, United States and China. Sustainability, 9(7): 1146. https://doi.org/10.3390/su9071146

[10] Central Electricity Regulatory Commission. (2003). Ministry of Law and Justice (Legislative Department). The Electricity Act.

[11] Ministry of New and Renewable Energy. (2016). Draft National Policy for Renewable Energy based Micro and Mini Grids.

[12] Palit, D., Bandyopadhyay, K.R. (2017). Rural electricity access in India in retrospect: A critical rumination. Energy Policy, 109: 109-120. https://doi.org/10.1016/j.enpol.2017.06.025

[13] Bhoyar, R.R., Bharatkar, S.S. (2013). Renewable energy integration in to microgrid: Powering rural Maharashtra State of India. In 2013 Annual IEEE India Conference (INDICON), https://doi.org/10.1109/INDCON.2013.6725877

[14] Census, Power for All West Bengal. 2011.

[15] Debajit Palit, (2012). Renewable energy mini grids Indian experiences.

[16] Bhandari, R., Sessa, V., Adamou, R. (2020). Rural electrification in Africa - A willingness to pay assessment in Niger. Renew. Energy, 161: 20-29. https://doi.org/10.1016/j.renene.2020.06.151

[17] Entele, B.R. (2020). Analysis of households' willingness to pay for a renewable source of electricity service connection: Evidence from a double-bounded dichotomous choice survey in rural Ethiopia. Heliyon, 6(2):

$\mathrm{e} 03332$. https://doi.org/10.1016/j.heliyon.2020.e03332

[18] Arega, T., Tadesse, T. (2017). Household willingness to pay for green electricity in urban and peri-urban Tigray, northern Ethiopia: Determinants and welfare effects. 
Energy $\quad$ Policy, 100: 292-300. https://doi.org/10.1016/j.enpol.2016.10.022

[19] Ntanos, S., Kyriakopoulos, G., Chalikias, M., Arabatzis, G., Skordoulis, M. (2018). Public Perceptions and Willingness to Pay for Renewable Energy: A Case Study from Greece. Sustainability, 10(3): 687. https://doi.org/10.3390/su10030687

[20] Dugoua, E., Liu, R., Urpelainen, J. (2017). Geographic and socio-economic barriers to rural electrification: New evidence from Indian villages. Energy Policy, 106: 278287. https://doi.org/10.1016/j.enpol.2017.03.048

[21] Quak, E. (2018). Lighting and electricity services for offgrid populations in sub-Sahara Africa. Institute of Development Studies.

[22] Stadler, M. (2018). Center for energy and innovative technologies. Research and Product Development.

[23] Nigam, A., Kaur, I., Sharma, K.K. (2019). Smart grid technology: A review. International Journal of Recent Technology and Engineering, 7(6): 243-247.

[24] Heynen, A.P., Lant, P.A., Smart, S., Sridharan, S., Greig, C. (019). Off-grid opportunities and threats in the wake of India's electrification push. Energy, Sustainability and Society, 9(1): 16. https://doi.org/10.1186/s13705-0190198-Z

[25] Graber, S., Narayanan, T., Alfaro, J., Palit, D. (2018). Solar microgrids in rural India: Consumers' willingness to pay for attributes of electricity. Energy for Sustainable Development, 42: 32-43. https://doi.org/10.1016/j.esd.2017.10.002

[26] Kabir, E., Kim, K.H., Szulejko, J.E. (2017). Social impacts of solar home systems in rural areas: A case study in Bangladesh. Energies, 10(10): 1615. https://doi.org/10.3390/en10101615

[27] Opiyo, N. (2016). A survey informed PV-based costeffective electrification options for rural sub-Saharan Africa. Energy Policy, 91: 1-11. https://doi.org/10.1016/j.enpol.2015.12.044

[28] Harrison, K., Adams, T. (2017). An evidence review: How affordable is off-grid energy access in Africa. https://acumen.org/wp-

content/uploads/2017/07/Evidence-Review-OnAffordability.pdf.

[29] Melhem, F.Y. (2018). Optimization methods and energy management in "smart grids". Electric Power, Université Bourgogne Franche-Comté.

[30] Reddy, S.S., Sandeep, V., Jung, C.M. (017). Review of stochastic optimization methods for smart grid. Front. Energy, 11(2): 197-209. https://doi.org/10.1007/s11708017-0457-7

[31] Balijepalli, V.S.K.M., Khaparde, S.A., Dobariya, C.V. (2010). Deployment of MicroGrids in India. In IEEE PES General Meeting, pp. 1-7. https://doi.org/10.1109/PES.2010.5589956
[32] Prasad, R., Kamath, R., Jagadisha, K., Girish, S. (2012). Smart DC Micro-grid for Effective Utilization of Solar Energy. International Journal of Scientific \& Engineering Research, 3(12): 1-4.

[33] Kumar Singh, V., Ravi Teja, L. (2015). Direct current and alternative current based solar micro-grid in rural energy infrastructure. Journal of Fundamentals of Renewable Energy and Applications, 6(1): 2-5. https://doi.org/10.4172/2090-4541.1000196

[34] Buragohain, T. (2012). Impact of solar energy in rural development in India. International Journal of Environmental Science and Development, 3(4): 334-338.

[35] Creswell, J.W., Clark, V.L.P. (2017). Designing and Conducting Mixed Methods Research. Sage Publications.

[36] Pawde, M.B., Saha, S.S. (1982). Geology of the Darjeeling Himalaya.

[37] Chawla, A., Pasupuleti, S., Chawla, S., Rao, A.C.S., Sarkar, K., Dwivedi, R. (2019). Landslide susceptibility zonation mapping: A case study from Darjeeling District, Eastern Himalayas, India. Journal of the Indian Society of Remote Sensing, 47(3): 497-511. https://doi.org/10.1007/s12524-018-0916-6

[38] Nunnally, J.C., Bernstein, I.H. (1967). McGraw-Hill Series in Psychology. Psychom. Theory, New York, NY, US McGraw-Hill.

[39] Creswell, J.W., Poth, C.N. (2017). Qualitative Inquiry and Research Design: Choosing Among Five Approaches. SAGE Publications.

[40] Labra, O., Castro, C., Wright, R., Chamblas, I. (2019). Thematic Analysis in Social Work: A Case Study. In Social Work Education, IntechOpen. https://doi.org/10.5772/intechopen.89464

[41] Blankenship, B., Wong, J.C.Y., Urpelainen, J. (2019). Explaining willingness to pay for pricing reforms that improve electricity service in India. Energy Policy, 128: 459-469. https://doi.org/10.1016/j.enpol.2019.01.015

[42] Abdullah, Zhou, D.Y., Shah, T., Jebran, K., Ali, S., Ali, A., Ali, A. (2017). Acceptance and willingness to pay for solar home system: Survey evidence from northern area of Pakistan. Energy Reports, 3: 54-60. https://doi.org/10.1016/j.egyr.2017.03.002

[43] Morrissey, K., Plater, A., Dean, M. (2018). The cost of electric power outages in the residential sector: A willingness to pay approach. Applied Energy, 212: 141150. https://doi.org/10.1016/j.apenergy.2017.12.007

[44] Sievert, M., Steinbuks, J. (2019). Willingness to Pay for electricity access in extreme poverty: Evidence from Sub-Saharan Africa. World Development, 128: 104859. https://doi.org/10.1016/j.worlddev.2019.104859

[45] Lee, C.Y., Lee, M.K., Yoo, S.H. (2017). Willingness to pay for replacing traditional energies with renewable energy in South Korea. Energy, 128: 284-290. https://doi.org/10.1016/j.energy.2017.04.037 